\title{
Study of Metabolic Diversity (Enzymatic Diversity) of Pantoea dispersa
}

\author{
Dipika Pandya $^{1 *}$, Vikram Solanki ${ }^{1}$, S. G. Patel $^{2}$ and S. A. Bhatt ${ }^{1}$ \\ ${ }^{1}$ Department of Life Science, Hemchandracharya North Gujarat University, Patan, India \\ ${ }^{2}$ Department of Plant Pathology, College of Agriculture, NAU, Bharuch Campus, India \\ *Corresponding author
}

\section{A B S T R A C T}

Keywords

Chitinase, CGTase, Xylanase, Pectinase

Article Info

Accepted:

15 January 2021

Available Online:

10 February 2021
Pantoea belong to a large group of organisms of the Enterobacteriaceae family, also called enteric bacilli. Enzymes are biocleaning agent without harmfully affecting environment. Pantoea dispersa are found with these potential which are metabolically diverse and produce different kinds of enzymes likes chitinase, CGTase, Pectinase, xylanase, Protease, L-Glutaminase etc. Extensive uses of agrochemicals create environmental pollution and severely affect living organisms. Pantoea has potential degrade harmful environmental pollutants. In present study nine different enzymes are selected for enzymatic profiling of Pantoea dispersa. Antimicrobial activity with different antibiogram was performed to check the sensitivity for the isolates. Qualitative assessment of these enzymes is carried out by standard protocol in which particular substrate of enzymes is used. Enzymatic activity was observed with the zone of utilization. Result of the study indicates that Pantoea dispersa is metabolically versatile as it produce all the enzymes viz., chitinase, xylanase, pectinase, CGTase, LGlutaminase, protease, glycosidase and cellulase. Result of antibiotic sensitivity show that Pantoea dispersa was sensitive against all the beta lactum group of antibiotic and some of the macrolide and glycoside group of antibiotics at given concentration.

\section{Introduction}

The genus Pantoea is a diverse group of yellow-pigmented, rod-shaped Gram-negative bacteria in the Enterobacteriaceae. Some of the first members were recognized as plant pathogens causing galls, wilting, soft rot and necrosis in a variety of agriculturally relevant plants, but since then, Pantoea strains have been frequently isolated from many aquatic and terrestrial environments, as well as in association with insects, animals and humans (Dutta et al., 2015; Adinarayana et al., 2003). Some Pantoea isolates produce antimicrobials, and have been developed into commercial biocontrol products, such as BlightBan C9-1 and Bloomtime Biological, to help control fire blight of apple and pear trees 
(Gohel et al., 2004), while others have bioremediation potential, with the capacity to degrade herbicides without the generation of toxic by-products. As well, some isolates have been harnessed as immunopotentiators for the development of supportive drugs for melanoma, infections, allergies and the reversal of immunosuppression. The ubiquity, versatility and genetic tractability of Pantoea isolates makes it an ideal group for not only exploring niche-specific adaptation and opportunism, but also for the development of commercially relevant medical, agricultural and environmental products (Kumar et al., 2012).

\section{Materials and Methods}

\section{Chitinase}

The medium used for the chitinase production plate assay was $(\mathrm{g} / \mathrm{l})$ chitin, 5.0; $\left(\mathrm{NH}_{4}\right)_{2} \mathrm{SO}_{4}$ 1.0; $\mathrm{MgSO}_{4} .7 \mathrm{H}_{2} \mathrm{O}, 0.5 ; \mathrm{KH}_{2} \mathrm{PO}_{4}, 1.36$; The $\mathrm{pH}$ of the medium was adjusted to 7.2. The medium was sterilized by autoclaving at 121 ${ }^{\circ} \mathrm{C}$ for 15 min. Then, Pantoea dispersa was streaked on the chitin agar plates containing calcofluor white M2R. The plates were incubated at $30{ }^{\circ} \mathrm{C}$ and examined under UV for the formation of clear Zone (CZ) around colonies up to 7 days. The size of clear zone and colony size were measured and the colony were transferred to chitin agar slant.

\section{Preparation of acid swollen chintin}

Phosporic acid swollen chitin was prepared according to the method given by Hackman. Phosphoric acid-swollen chitin was prepared according to the method described by Hackman (1962). 10g chitin powder was taken for the preparation. While shaking at $4^{\circ} \mathrm{C}$ $8^{\circ} \mathrm{C}$ add slowly $88 \%$ phosphoric acid then crush and mix chitin with $\mathrm{H}_{3} \mathrm{PO}_{4}$ for 2 hrs. Add this chitin with $\mathrm{H}_{3} \mathrm{PO}_{4}$ in chilled distilled water shake properly get swollen chitin. After several time wash with cold distilled water add the wash with $1 \% \mathrm{NaHCO}_{3}$ till acidity removed. Suspended this in sterile chilled distilled water. Blend to make homogening suspension.

Chitinase activity is checked by preparing minimal salt medium with acid swollen chitin and Calcoflor M2R white. Chitinase activity is checked by observing plate under UV light.

\section{Xylanase}

Soil is rich and diverse source of microorganism. Microbes isolated from the soil which is dumped with fruit and vegetables have potential to degrade varied biopolymer. Pantoea spp. isolated from the vegetable market soil is screened for xylanase activity. Nutrient agar plates are prepared with $1 \%$ xylan area used as screening of xylanse activity. These xylan containing $\mathrm{N}$-agar plates are streaked with young culture of Pantoea and incubated at $30{ }^{\circ} \mathrm{C}$ for $48 \mathrm{hrs}$. After the incubation plates are examined for growth. Xylanase activity is checked by adding $0.1 \%$ aquesous congo red solution. Plates were flood with congo red and incubated for 15 mins. Excess congo-red drained and plate are destained with $1 \mathrm{M} \mathrm{NaCl}$ solution. This removed unbound congo-red. Congo red has good affinity for xylan. Surrounding the colonies where xylan is utilised will give clear halos. While in rest of the part of plate congo red is bind with xylan and give red color.

\section{Pectinase}

Soil is major platform for the growth of diverse group of microorganism. These microbes have different kind of activity. The pectinase producing microbes isolated from the soil which is dumped with fruit and vegetables. Pantoea spp. Isolated from the vegetable market soil is screened for pectinase activity. 
Pectin agar plate are streaked with young culture of Pantoea spp. and incubated at $30^{\circ} \mathrm{C}$ for 48 hours. After the incubation plates are examined for growth. Pectinase activity is checked by adding $1 \%$ cetyl -tri methyl ammonium bromide (CTAB) solution and incubated for 15 minute and observe for clear halo surrounding colony.

\section{CGTase}

CGTase activity was checked by method given by Illias et al., 2002. Screening of CGTase producer on Basal Horikoshi (II) medium consists of $(\% \mathrm{w} / \mathrm{v})$ : soluble starch $(1 \%)$, peptone $(0.5 \%)$, yeast extract $(0.5 \%)$, MgSO4 (0.002\%), K2HPO4 (0.1\%), Phenolphathalein (0.002\%),Agar $(2.5 \%)$ and $\mathrm{Na}_{2} \mathrm{CO}_{3}$ (1\%) (autoclaved separately), $\mathrm{pH}$ 7.5. Pantoea dispersa streak on this plate and incubate it at $28{ }^{\circ} \mathrm{C}$. After incubation clear halos surrounding colonies indicates CGTase activity.

\section{L-Glutaminase}

Pantoea dispersa was tested for Lglutaminase activity. The L- glutamine containing media were supplemented with $0.135 \mu \mathrm{l}$ of $2.5 \%$ of phenol red as an indicator. The two control plates were also prepared for glutamine - one was without dye while the other was without glutamine (using $\mathrm{NaNO}_{3}$ as a nitrogen source). L-glutaminase activity was identified by formation of a pink zone around colonies.

\section{Protease}

Protease activity was checked by using milk agar plate. The diluted samples were streaked onto skim milk agar plates containing peptone $(0.1 \% \mathrm{wt} / \mathrm{vol}), \mathrm{NaCl}(0.5 \% \mathrm{wt} / \mathrm{vol})$, agar $(2.0 \% \mathrm{wt} / \mathrm{vol})$, and skim milk (10\% vol/vol). Plates were incubated at $37^{\circ} \mathrm{C}$ for 24 hours. A clear halos surrounding the colonies indicates hydrolysis of milk by Pantoea dispersa gave an indication of protease activity.

\section{Lipase}

Lipase activity was checked on tributyrin agar medium. Lipase producing microorganisms produced a zone of clearance (hydrolysis) when diluted samples were spread on the TBA medium containing per liter of peptone, $5 \mathrm{~g}$; beef extract, 3g; tributyrin, $10 \mathrm{ml}$ and agaragar, 20g. The zone of tributyrin hydrolysis was checked after 24 and $48 \mathrm{~h}$ of incubation at $37^{\circ} \mathrm{C}$.

\section{$\beta$-Glucosidase}

Screening of $\beta$-Glucosidase activity was carried out on MRS agar that is supplemented with esculin (3 $\mathrm{g} / \mathrm{l})$ and ferric ammonium citrate $(0.2 \mathrm{~g} / \mathrm{l})$. The plates were incubated at $37^{\circ} \mathrm{C}$ for about $48 \mathrm{~h}$ and colonies producing browning or blackening of the medium were noted as positive for $\beta$-Glucosidase. Young and active culture of Pantoea dispersa was streaked over the plate and plate was kept for $48 \mathrm{hrs}$ at room temperature.

\section{Cellulase}

For screening of Cellulase activity carboxy methyl cellulose substrate containing minimal medium are prepared and active culture Pantoea dispersa was used to check the cellulose activity. After sufficient growth $0.5 \%$ congo red solution was applied and keep it for 15 minutes and excess congo red is drain away. This plate then destained with the help of 1M Nacl solution. Presence of clear halos surrounding the colonies indicates cellulose activity.

\section{Antibiotic Sensitivity}

Pantoea spp. was studied for sensitivity to different antibiotic. This was carried out with 
respect to various multidisc having different antibiotics. On $\mathrm{N}$-agar plate culture was spreaded with the help of sterile spreader and multidisc is kept on their aseptically.

After incubation of $48 \mathrm{hrs}$ results are note down. For the antibiotic sensitivity multidisc with the different antibiotics are used.

\section{Results and Discussion}

\section{Chitinase}

Chitin agar plates containing calcofluor white M2R was streaked the plate inoculated with Pantoea dispersa and after incubation the plates are examined under UV for the formation of clear Zone (CZ) around colonies up to 7 days. Results indicate that colonies of Pantoea dispersa produces clear halos surrounding the colonies. Pantoea dispersa is good producer of chitinase enzyme (Fig. 1).

\section{Xylanase}

Addition of $0.1 \%$ congo red and subsequent destain with $1 \mathrm{M} \mathrm{NaCl}$ indicates the Pantoea dispersa has xylanase activity. Results showed that addition of congo red bind to the xylan molecule and whole plate looks red color. Subsequent addition of destain remove unbind congo red stain and surrounding the colonies clear halos are seen this indicate xylanase activity of Pantoea dispersa.

\section{Pectinase}

Pectin agar medium containing plates are inoculated with Pantoea dispersa and after growth plates were flooded with $1 \%$ Cetyl trimethyl ammonium bromide solution surrounding colonies pectin was not precipitated that indicated pectinase activity. CTAB precipitate the pectin molecule if organism produces pectinase surrounding the colonies pectin is utilised and clear halos are produced that indicate pectinase activity by Pantoea dispersa.

\section{CGTase}

Screening of the CGTase activity was carried out on the medium having starch. If organism produce CGTase enzyme it will convert starch into $\beta$ - cyclodextrin.

After incubation period of $48 \mathrm{hrs}$ plate is flood with Phenolphathalein solution. This reacts with starch molecule and produces pink to yellow color. Surrounding the colonies of Pantoea dispersa there were no color (clear halos) indicates CGTase activity.

\section{L-Glutaminase}

L-Glutaminase activity was checked on plate having L-Glutamine. Actively growing culture of Pantoea dispersa was streaked on this plate and incubated at $48 \mathrm{hrs}$ at room temperature. After incubation no pink colored colonies are produced that indicates absence of Lglutaminase activity by Pantoea dispersa.

\section{Protease}

Activated culture of Pantoea dispersa was streaked on milk agar plate and plates are incubated at $37{ }^{\circ} \mathrm{C}$ for $48 \mathrm{hrs}$. After incubation no clear halos are produced which indicates no protease activity by Pantoea dispersa.

\section{Lipase}

Twenty four hrs actively growing culture of Pantoea dispersa was streaked on Tributyrin agar plate and plated incubated at room temperature for $48 \mathrm{hrs}$. After incubation plates are observed for colonies of Pantoea dispersa have greening color that indicates the lipase production by Pantoea dispersa. 
Table.1

\begin{tabular}{|c|c|c|c|}
\hline \multicolumn{3}{|c|}{ Concentration } & Sensitivity \\
\hline \multicolumn{4}{|c|}{ COMBI 69} \\
\hline Ciprofloxacin & & $5 \mu \mathrm{g}$ & Yes \\
\hline Oflaxacin & & $5 \mu \mathrm{g}$ & Yes \\
\hline Sparfloxacin & & $5 \mu \mathrm{g}$ & Yes \\
\hline Gatifloxacin & & $5 \mu \mathrm{g}$ & Yes \\
\hline Aztreonam & & $30 \mu \mathrm{g}$ & Yes \\
\hline Azithromycin & & $15 \mu \mathrm{g}$ & Yes \\
\hline Vancomycin & & $30 \mu \mathrm{g}$ & Yes \\
\hline Doxycycline & & $30 \mu \mathrm{g}$ & Yes \\
\hline \multicolumn{4}{|c|}{ COMBI 95} \\
\hline Ceftizoxime ( & & $30 \mu \mathrm{g}$ & Yes \\
\hline Ceftriaxone & & $30 \mu \mathrm{g}$ & Yes \\
\hline Cefuroxime ( & & $30 \mu \mathrm{g}$ & Yes \\
\hline Cefadroxil ( & & $30 \mu \mathrm{g}$ & Yes \\
\hline Co-Trimoxazol & & $25 \mu \mathrm{g}$ & Yes \\
\hline Doxycycline $\mathbf{H}$ & & $30 \mu \mathrm{g}$ & Yes \\
\hline Gatifloxacin & & $5 \mu \mathrm{g}$ & Yes \\
\hline Gentamicin ( & & $10 \mu \mathrm{g}$ & Yes \\
\hline \multicolumn{4}{|c|}{ COMBI 516} \\
\hline Imipenem (1 & & $10 \mu \mathrm{g}$ & Yes \\
\hline Meropenem ( & & $10 \mu \mathrm{g}$ & Yes \\
\hline Amoxyclav & & $30 \mu \mathrm{g}$ & Yes \\
\hline Ampicillin/Sulbac & & $10 / 10 \mu g$ & Yes \\
\hline Azithromycin & & $15 \mu \mathrm{g}$ & Yes \\
\hline Vancomycin & & $30 \mu \mathrm{g}$ & Yes \\
\hline Linezolid ( & & $30 \mu \mathrm{g}$ & Yes \\
\hline Nitrofurantoir & & $300 \mu \mathrm{g}$ & Yes \\
\hline \multicolumn{4}{|c|}{ G- III Plus } \\
\hline Amikacin ( & & $10 \mu \mathrm{g}$ & Yes \\
\hline Amoxycillin ( & & $10 \mu \mathrm{g}$ & No \\
\hline Bacitracin & & 10Unit & No \\
\hline Cephalothin & & $30 \mu \mathrm{g}$ & Yes \\
\hline Erythromyc & & $15 \mu \mathrm{g}$ & Yes \\
\hline Novobiocin & & $30 \mu \mathrm{g}$ & Yes \\
\hline Oxytetracycli & & $30 \mu \mathrm{g}$ & Yes \\
\hline Vancomycin & & $30 \mu \mathrm{g}$ & Yes \\
\hline \multicolumn{4}{|c|}{ COMBI 61} \\
\hline Imipenem (1) & & $10 \mu \mathrm{g}$ & Yes \\
\hline
\end{tabular}




\begin{tabular}{|c|c|c|}
\hline Meropenem (MRP) & $10 \mu \mathrm{g}$ & Yes \\
\hline Ciprofloxacin (CIP) & $5 \mu \mathrm{g}$ & Yes \\
\hline Tobramycin (TOB) & $10 \mu \mathrm{g}$ & Yes \\
\hline Moxifloxacin (MO) & $5 \mu \mathrm{g}$ & Yes \\
\hline Ofloxacin (OF) & $5 \mu \mathrm{g}$ & Yes \\
\hline Sparfloxacin (SPX) & $5 \mu \mathrm{g}$ & Yes \\
\hline Levofloxacin (LE) & $5 \mu \mathrm{g}$ & Yes \\
\hline & & \\
\hline & COMBI VII & \\
\hline Amoxycillin (AMX) & $10 \mu \mathrm{g}$ & No \\
\hline Cloxacillin (COX) & $5 \mu \mathrm{g}$ & No \\
\hline Erythromycin (E) & $15 \mu \mathrm{g}$ & Yes \\
\hline Tetracycline (TE) & $10 \mu \mathrm{g}$ & Yes \\
\hline Penicillin (P) & $2 \mathrm{Unit}$ & No \\
\hline Co-Trimoxazole (COT) & $25 \mu \mathrm{g}$ & Yes \\
\hline Penicillin-V (PV) & $3 \mu \mathrm{g}$ & Yes \\
\hline Cefalexin (CN) & $30 \mu \mathrm{g}$ & Yes \\
\hline
\end{tabular}

Fig.1
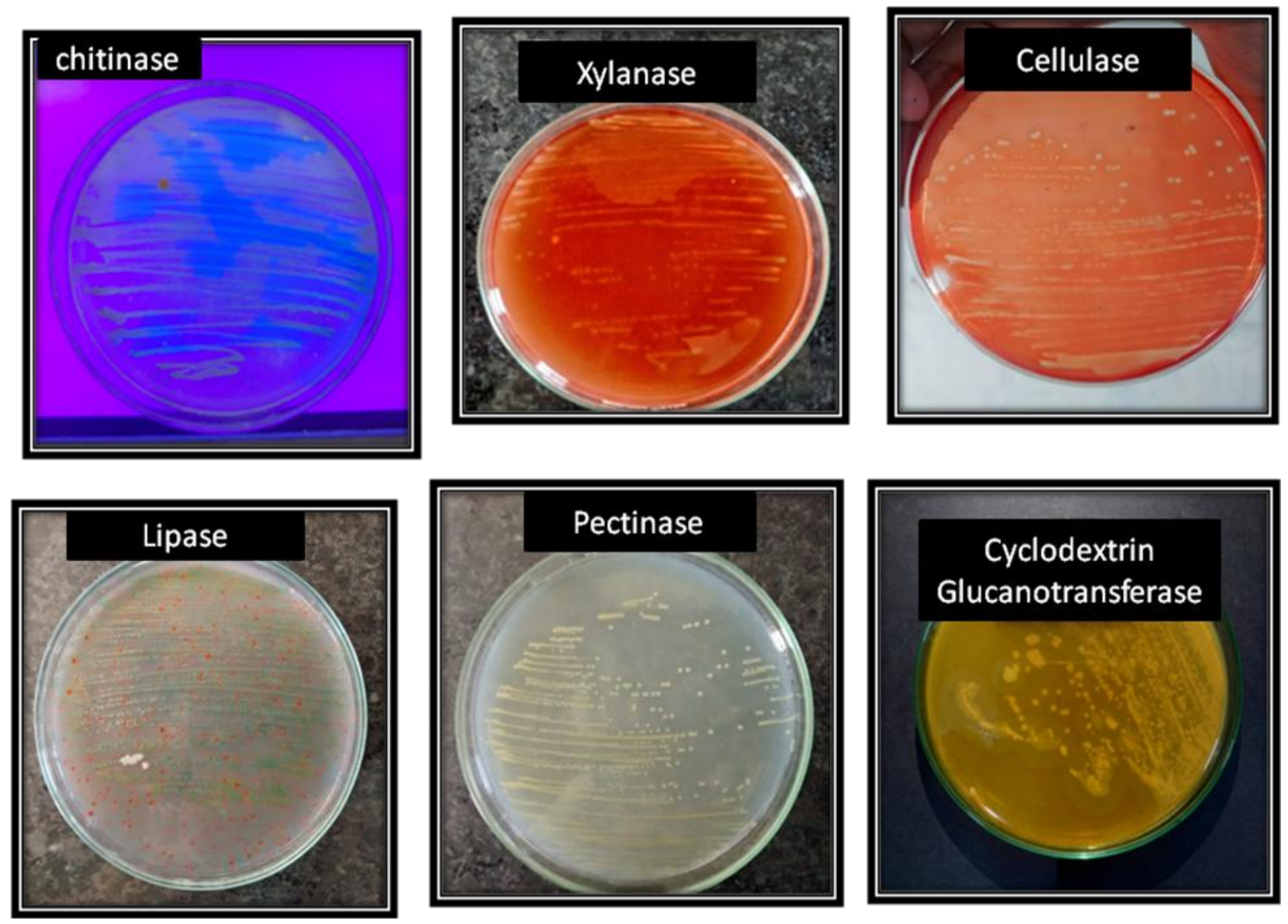


\section{$\beta$ - Glucosidase}

After incubation of $48 \mathrm{hrs}$ plates was observed for the color change. No development of brown or black colored indicates Pantoea dispersa is not producing $\beta$ - Glucosidase.

\section{Cellulase}

Carboxy methyl cellulose containing medium are inoculated with young and active culture of Pantoea dispersa. These plates are incubated at room temperature for $72 \mathrm{hrs}$. These plates are then flood with agar are then flood with congo red solution and then it is destain with $1 \mathrm{M} \mathrm{NaCl}$ solution. Results indicates that the $P$. dispersa has ability to degrade cellulose.

\section{Antibiotic Sensitivity}

Pantoea spp. found to be sensitive for almost all the antibiotics used in experiment. It was remain unaffected with almost all the antibiotics used in experiment. Results of antibiotic sensitivity are shown in Table 1 . Pantoea dispersa found to be sensitive for Ciprofloxacin, Ofloxacin, Sparfloxacin, Gatifloxacin, Aztreonam, Azithromycin, Vancomycin, Doxycycline used in experiment.

It was remain unaffected with Bacitracin, Cephalothin, Amoxycillin, Cloxacillin and Penicillin. Result of this study indicates the Pantoea dispersa is metabolically diverse and produce very important enzymes chitinase, xylanase, CGTase, Lipase, Pectinase and cellulose.
They lack to produce L- glutaminase, $\beta$ Glucosidase and protease. This indicates role of Pantoea dispersa as a Biocontrol agent as a future scope.

\section{References}

VYAS, P., Jiwan, D., and CHHATPAR, H. (2005). Statistical Optimization of Chitinase Production by Pantoeadispersato Enhance Degradation of Crustacean Chitin Waste. Journal of microbiology and biotechnology, 15(1), 197-201.

Gohel, V., Chaudhary, T., Vyas, P., and Chhatpar, H. S. (2004). Isolation and identification of marine chitinolytic bacteria and their potential in antifungal biocontrol.

Dutta, S., Roy, R., and Lahiri, D. (2015). LAsparaginase and L-Glutaminase FROM Pseudomonas aeruginosa: Production and some physicochemical properties. The Journal of Microbiology, Biotechnology and Food Sciences, 5(1), 34.

Adinarayana, K., Ellaiah, P., and Prasad, D. S. (2003). Purification and partial characterization of thermostable serine alkaline protease from a newly isolated Bacillus subtilis PE-11. Aaps Pharmscitech, 4(4), 440-448.

Kumar, D., Kumar, L., Nagar, S., Raina, C., Parshad, R., and Gupta, V. K. (2012). Screening, isolation and production of lipase/esterase producing Bacillus sp. strain DVL2 and its potential evaluation in esterification and resolution reactions. Archives of Applied Science Research, 4(4), 1763-1770.

\section{How to cite this article:}

Dipika Pandya, Vikram Solanki, S. G. Patel and Bhatt, S. A. 2021. Study of Metabolic Diversity (Enzymatic Diversity) of Pantoea dispersa. Int.J.Curr.Microbiol.App.Sci. 10(02): 1550-1556. doi: https://doi.org/10.20546/ijcmas.2021.1002.184 